Braz J Med Biol Res, September 2011, Volume 44(9) 827-835

doi: 10.1590/S0100-879X2011007500075

Aerobic exercise training in heart failure: impact on sympathetic hyperactivity and cardiac and skeletal muscle function

P.C. Brum, A.V.N. Bacurau, A. Medeiros, J.C.B. Ferreira, A.S. Vanzelli and C.E. Negrão

\section{QR $C N P q$}

da Ciência Ministério

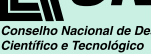

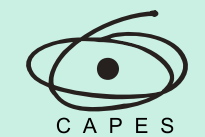

Ministério da Educação

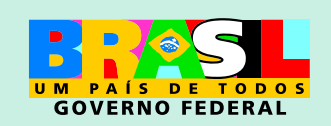

Institutional Sponsors

soiplo
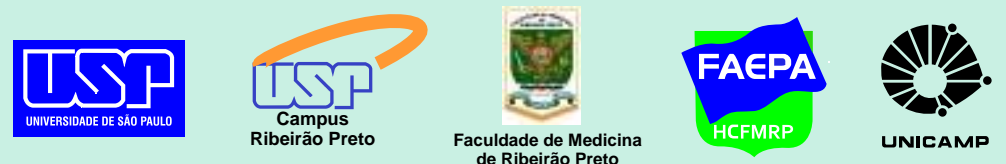

Ф SHIMADZU

Explore High - Performance MS

analitica Thermo 


\title{
Aerobic exercise training in heart failure: impact on sympathetic hyperactivity and cardiac and skeletal muscle function
}

\author{
P.C. Brum ${ }^{1}$, A.V.N. Bacurau ${ }^{1}$, A. Medeiros ${ }^{1,2}$, J.C.B. Ferreira ${ }^{1,3}$, A.S. Vanzelli ${ }^{1}$ \\ and C.E. Negrão $0^{1,4}$
}

${ }^{1}$ Departamento de Biodinâmica do Movimento do Corpo Humano, Escola de Educação Física e Esporte, Universidade de São Paulo, São Paulo, SP, Brasil

2Departamento de Biociências, Universidade Federal de São Paulo, Santos, SP, Brasil

${ }^{3}$ Department of Chemical and Systems Biology, Stanford University, Palo Alto, CA, USA ${ }^{4}$ Instituto do Coração, Faculdade de Medicina, Universidade de São Paulo, São Paulo, SP, Brasil

\begin{abstract}
Heart failure is a common endpoint for many forms of cardiovascular disease and a significant cause of morbidity and mortality. Chronic neurohumoral excitation (i.e., sympathetic hyperactivity) has been considered to be a hallmark of heart failure and is associated with a poor prognosis, cardiac dysfunction and remodeling, and skeletal myopathy. Aerobic exercise training is efficient in counteracting sympathetic hyperactivity and its toxic effects on cardiac and skeletal muscles. In this review, we describe the effects of aerobic exercise training on sympathetic hyperactivity, skeletal myopathy, as well as cardiac function and remodeling in human and animal heart failure. We also discuss the mechanisms underlying the effects of aerobic exercise training.
\end{abstract}

Key words: Heart failure; Exercise training; Sympathetic hyperactivity; Ventricular function; Cardiac remodeling; Skeletal myopathy

\section{Introduction}

Heart failure (HF) is a syndrome of poor prognosis and high health care costs (1) characterized by dyspnea and exercise intolerance as a consequence of low cardiac output. It is a common endpoint for many forms of cardiovascular diseases. More than 20 million people worldwide are estimated to have HF (1), and this situation is more critical considering that the prevalence of $\mathrm{HF}$ will rise as the mean age of the population increases. The development of HF involves a continuous interaction between myocardial dysfunction and a compensatory activation of neurohumoral systems such as sympathetic and renin-angiotensin-aldosterone hyperactivity to name a few (2). At first, this response is compensatory, but sustained neurohumoral hyperactivity is toxic $(3,4)$ and portends a poor prognosis (5). HF treatment aims to improve prognosis and control symptoms by blocking neurohumoral hyperactivity with the use of $\beta$-adrenoceptor blockers, inhibitors of angiotensin-converting enzyme
(ACE), angiotensin II receptor blockers and inhibitors of aldosterone synthesis, and by controlling fluid retention (6). Even though neurohumoral blockade is associated with a better prognosis $(7)$, reversal remodeling $(4,8,9)$ and improved cardiac calcium handling (9), HF remains a major cause of illness and death. Thus, new strategies for HF treatment and prevention are among the great challenges facing health sciences today.

In patients with stable HF, exercise training can relieve symptoms, improve exercise tolerance and quality of life, and reduce hospitalization (10). In addition, current treatment guidelines recommend aerobic exercise training to HF patients in functional classes II and III according to the New York Heart Association (11).

In the present review, we discuss the effects of aerobic exercise training on HF with focus on neurohormonal hyperactivity and its toxic effects on cardiac and skeletal muscles.

Correspondence: P.C. Brum, Departamento de Biodinâmica do Movimento do Corpo Humano, Escola de Educação Física e Esporte, USP, Av. Prof. Mello Moraes, 65, 05508-900 São Paulo, SP, Brasil. Fax: +55-11-3813-5921. E-mail: pcbrum@usp.br

Presented at the XV Simpósio Brasileiro de Fisiologia Cardiovascular, São Paulo, SP, Brazil, February 2-5, 2011.

Received February 4, 2011. Accepted June 6, 2011. Available online June 17, 2011. Published September 16, 2011. 


\section{Effects of exercise training on the sympathetic nervous system}

The beneficial effects of exercise training in HF are associated with neural control of the cardiovascular system $(12,13)$. These effects include reduction of sympathetic outflow in exercised humans $(14,15)$ and animals $(16-18)$ with HF. The sympathetic toxicity of cardiac (17-21) and skeletal (22-24) muscles in HF is also reduced by exercise training. Since morbidity and mortality in cardiovascular disease are often associated with increases of sympathetic nerve activity, exercise training becomes a potent nonpharmacological strategy for HF therapy.

Coats et al. (25) were the first to report that exercise training changes the parasympathetic/sympathetic balance. Exercise training reduced by $16 \%$ whole-body radiolabeled norepinephrine spillover in HF patients (26). Additionally, these investigators also observed an enhanced parasympathetic control of heart rate paralleled by a decreased sympathetic dominance in exercised HF patients. This is particularly interesting since parasympathetic dysfunction parallels sympathetic hyperactivation in HF (27). Therefore, HF therapies that increase cholinergic activity (28) and/or decrease adrenergic hyperactivity (9) should combine exercise training to optimize the benefits on the cardiovascular system. In this context, we have demonstrated an additional reduction in muscular sympathetic nerve activity by exercise training in HF patients optimized with carvedilol, a third generation $\beta$-blocker $\left(\beta_{1}\right.$ - and $\beta_{2}$-blockade) with an $\alpha$-blockade and vasodilatory effect (14). Additionally, while $\beta$-blocker therapy had no impact on exercise capacity in humans or animals with $\mathrm{HF}(6,9)$, a $\beta$-blocker combined with exercise training improved exercise capacity $(14,19)$.

The reduction of sympathetic activity by exercise training in HF patients is associated with a better clinical outcome $(14,15)$. We have demonstrated by direct assessment of muscular sympathetic nerve activity that a 4-month period of moderate exercise training leads to a significant reduction in resting sympathetic activity (Figure 1) associated with improved peak oxygen uptake and exercise tolerance in class II and III New York Heart Association chronic HF patients (15). It is important to emphasize that the sympathetic activity was so dramatically reduced by exercise training that it returned to the values of age-matched, healthy controls.

The mechanisms underlying reduced sympathetic nerve activity by exercise training are still a topic of major interest under current investigation. One of the potential candidates for sympathetic reduction by exercise training is the afferent autonomic control of sympathetic nerve activity coordinated by arterial baroreceptors, cardiopulmonary receptors, ergoreceptors, and chemoreceptors (29-35)

We have demonstrated that exercise training reduces renal sympathetic nerve activity associated with increased arterial baroreceptor afferent sensitivity in control rats $(29,31)$. Interestingly, this knowledge was extended to HF by Liu et al. (30), who observed reestablished arterial baroreflex control to heart rate and renal sympathetic nerve activity by exercise training in a rabbit model of pacinginduced HF. The same investigators also demonstrated that this response was mainly parasympathetic-mediated since atropine blocked the improved baroreflex control of heart rate by exercise training (36). In addition, we also demonstrated that improved baroreflex control of renal sympathetic nerve activity in a rat model of myocardial infarction was associated with increased aortic depressor nerve sensitivity (13).

Exercise training also exerts important effects on chemoreflex and cardiopulmonary reflex (35). Enhanced chemoreflex control was decreased by exercise training in a rabbit model of HF (34). Conversely, depressed cardiopulmonary reflex was ameliorated by exercise training in rabbits with HF (33). Indeed, HF is paralleled by ergoreflex overactivity and aerobic exercise training reduced the abnormal response to exercise partially due to a reduction of ergoreceptor excitation (32).

Since the arterial baroreflex, chemoreflex and cardiopulmonary reflex control are all integrated in the central nervous system and exercise training reestablished the functioning of these reflexes, one might suggest that exercise training plays an important role in the control of these cardiovascular reflexes by the central nervous system. In fact, the impact of exercise training on central nervous system control of cardiovascular reflexes has been studied (37). Reduced AT1 receptors of angiotensin II in the rostral ventrolateral
Before ET MSNA = 72 bursts $/ \mathrm{min}$

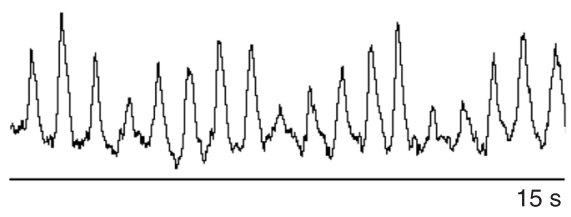

After ET

MSNA $=40$ bursts $/ \mathrm{min}$

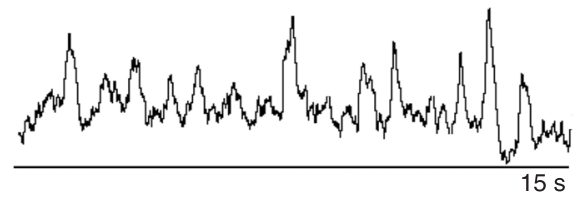

Figure 1. Muscle sympathetic nerve activity (MSNA) of a 58-year-old female heart failure patient (hypertensive cardiomyopathy) with a 36\% ejection fraction before and after 4 months of exercise training (ET). MSNA was obtained by direct recording of muscle sympathetic discharge by microneurography. Note that exercise training dramatically reduced sympathetic discharge. 
medulla and nucleus tractus solitarii, and normalized ACE and ACE2 levels in the brain of HF animal models have been proposed as major mechanisms (38).

\section{Impact of exercise training on cardiac function}

It is widely recognized that aerobic exercise training improves cardiac pump capacity. However, the effects of aerobic exercise training on cardiac function in HF are still controversial. While some studies and a meta-analysis (39) failed to show any improvement in cardiac function of HF individuals, other studies demonstrated significant increased cardiac contractility and function in human HF (40). It is important to emphasize that, despite these contradictory data, aerobic exercise training does improve myocardial blood flow reserve independently of improved ventricular function (41). This is of particular interest and clinically relevant, since abnormal coronary flow reserve can be considered an independent predictor of survival in idiopathic dilated cardiomyopathy (42).

Regarding the contradictory results about the effect of aerobic exercise training on cardiac function of HF individuals, some variables such as aerobic exercise training intensity and regimens adopted by each study, as well as the methods used to evaluate cardiac function in human studies, might have influenced the results observed. Interestingly, Haykowsky et al. (40) conducted a meta-analysis of fourteen studies and observed that the exercise intensity adopted in training sessions plays an important role in the magnitude of cardiovascular adaptation in HF patients. They observed that aerobic exercise training sessions performed at intensities above $60 \%$ of $\mathrm{VO}_{2}$ peak are more suitable, leading to improvement of cardiac function in HF patients. In fact, Wisloff et al. (43) recently suggested that a threshold intensity (at which an exercise session has to be executed) might exist to benefit the heart intrinsically. They showed that high-intensity interval training (95\% of maximal heart rate) rather than continuous training ( $70 \%$ of maximal heart rate) improved ejection fraction and led to reverse left ventricle remodeling (43). This result has been consistently reproduced by these investigators in patients with severe cardiac dysfunction.

In animal models of HF, studies using invasive methodologies demonstrated improved cardiac function by aerobic exercise training $(17,18)$, which led to further studies focusing on the mechanisms underlying these beneficial effects. Ventricular function is tightly coupled to $\mathrm{Ca}^{2+}$ transients in the heart. Several $\mathrm{Ca}^{2+}$-handling proteins are involved in the maintenance of normal cardiac $\mathrm{Ca}^{2+}$ homeostasis and contractile function. Among these proteins, sarcoplasmic reticulum $\mathrm{Ca}^{2+}$ ATPase (SERCA2), ryanodine receptor (RyR), and the $\mathrm{Na}^{+} / \mathrm{Ca}^{2+}$ exchanger (NCX) are responsible for the balance between sarcoplasmic $\mathrm{Ca}^{2+}$ uptake and release, and extrusion by sarcolemma, respectively. Abnormal $\mathrm{Ca}^{2+}$ homeostasis by perturbation in the expression or function of these major $\mathrm{Ca}^{2+}{ }^{2}$-regulating proteins has been described in severe $\mathrm{HF}$ (44). In this context, we have suggested that exercise training would improve cardiac function in HF animals by, changing, at least in part, the expression of proteins involved in cardiac $\mathrm{Ca}^{2+}$ homeostasis. We found that exercise training significantly increased fractional shortening toward normal levels and improved the net balance of cardiac $\mathrm{Ca}^{2+}$ proteins involved in $\mathrm{Ca}^{2+}$ transsarcolemmal flux and sarcoplasmic reticulum $\mathrm{Ca}^{2+}$ reuptake in a genetic model of sympathetic hyperactivity-induced $\mathrm{HF}$ based on $\alpha_{2 A}$ and $\alpha_{2 C}$ adrenoceptor gene inactivation in mice $\left(\alpha_{2 A} /\right.$ $\left.\alpha_{2 C} A R K O\right)$ (18). At 7 months of age, when $\alpha_{2 A} / \alpha_{2 C} A R K O$ mice display severe $\mathrm{HF}$, exercise training restored cardiac NCX expression levels, and increased SERCA2, and phosphorylated phospholamban expression levels at both residues Ser ${ }^{16}$ and $\mathrm{Thr}^{17}$, which resulted in improved left ventricular function. These findings suggest that the improvement in intracellular $\mathrm{Ca}^{2+}$ regulation is a molecular mechanism underlying the benefits of exercise training for overall ventricular function in severe HF (18).

Accumulated evidence shows that exercise training is an important strategy not only for the treatment but also for the prevention of cardiovascular diseases (17). Accordingly, we carried out an investigation to test whether exercise training would decrease sympathetic activity and delay the onset of ventricular dysfunction in $\alpha_{2 A} / \alpha_{2 C} A R K O$ mice (17). To test this hypothesis, we studied $\alpha_{2 A} / \alpha_{2 C} A R K O$ mice aged 3-5 months before HF was established. We showed that exercise training prevented systolic dysfunction, restored SERCA2 expression and the phosphorylation of RyR at Ser 2809 to the levels of control mice, and increased the phosphorylation of phospholamban at $\operatorname{Ser}^{16}$ (17). The reduced expression of phospho-Ser 2809 -RyR in exercise-trained $\alpha_{2 A} / \alpha_{2 C} A R K O$ mice toward control levels seems to be beneficial because chronic hyperphosphorylation of RyR is associated with diastolic $\mathrm{Ca}^{2+}$ leak, leading to arrythmogenicity (45) and cardiac dysfunction. In addition, NCX expression remained decreased in exercise-trained $\alpha_{2 A} / \alpha_{2 C} A R K O$ mice. These results suggest that the mechanisms underlying the improvement of ventricular function include the prevention of cardiac $\mathrm{Ca}^{2+}$ handling abnormalities by changing the phosphorylation status of proteins involved in sarcoplasmic $\mathrm{Ca}^{2+}$ release and reuptake.

Of interest, our results have been corroborated by other investigators studying different animal models of HF (46). In addition, enhanced myofilament $\mathrm{Ca}^{2+}$ sensitivity induced by exercise training in HF has also been observed (47). Taken together, our studies and others suggest the preventive and therapeutic effects of exercise training on cardiac function by improving $\mathrm{Ca}^{2+}$ homeostasis. The summary of the main results is shown in Figure 2. 


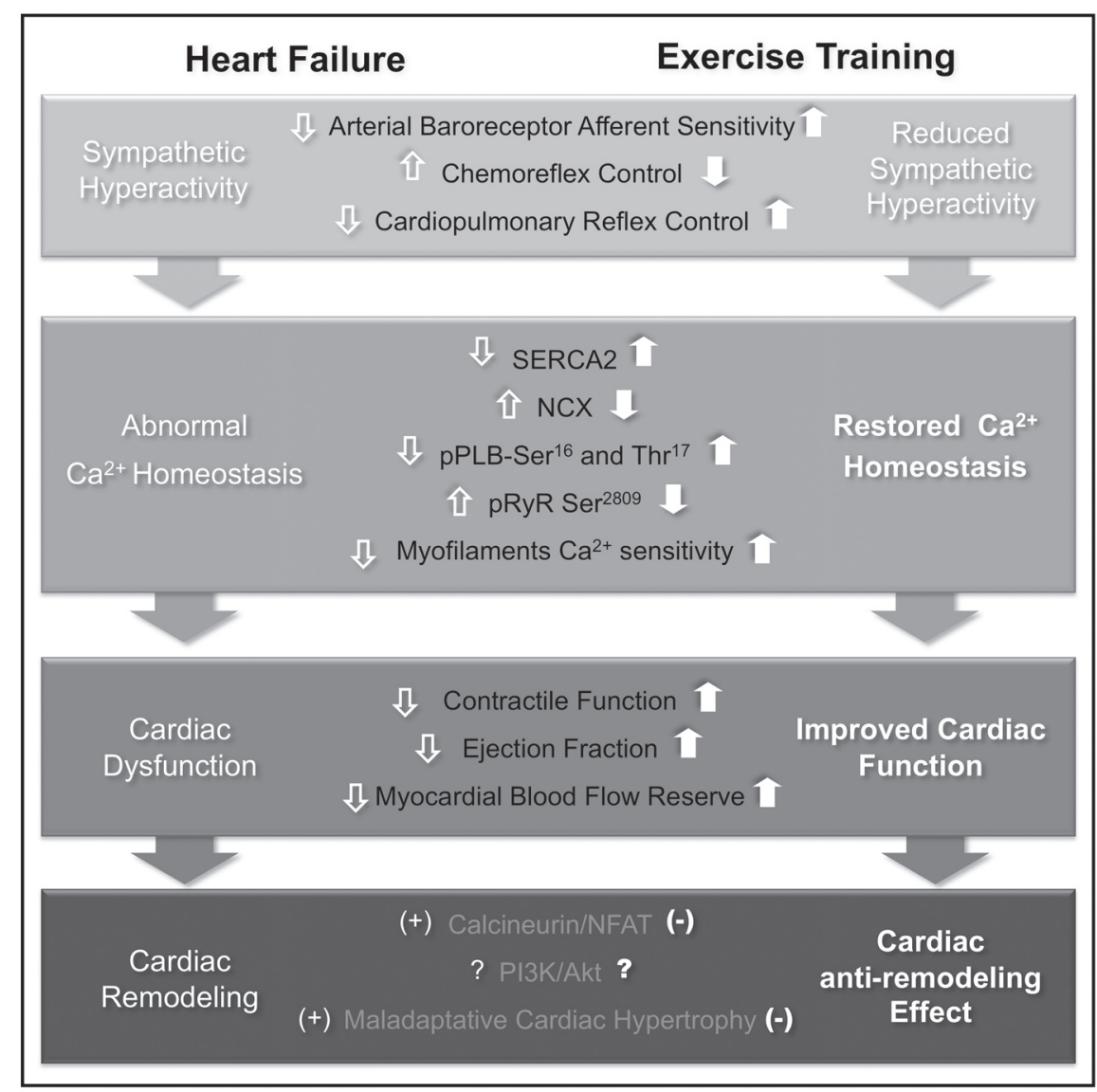

Figure 2. Effects of exercise training on cardiac function and remodeling. Note that sympathetic hyperactivity in heart failure is linked to altered afferent autonomic control by arterial baroreceptors, cardiopulmonary receptors and chemoreceptors. Additionally, cardiac dysfunction and remodeling in heart failure are associated with impaired $\mathrm{Ca}^{2+}$ homeostasis by altered expression of $\mathrm{Ca}^{2+}$-handling proteins and myofilament $\mathrm{Ca}^{2+}$ sensitivity, as well as activation of the calcineurin/NFAT signaling pathway. Interestingly, exercise training decreases sympathetic nerve activity and re-establishes $\mathrm{Ca}^{2+}$ homeostasis, which ultimately contributes to improved cardiac function and anti-remodeling. SERCA2 $=$ sarcoplasmic reticulum $\mathrm{Ca}^{2+} \mathrm{AT}-$ Pase; $\mathrm{NCX}=\mathrm{Na}^{+} / \mathrm{Ca}^{2+}$ exchanger; pPLB-Ser ${ }^{16}$ and $\mathrm{Thr}^{17}=$ phosphorylated phospholamban at both Ser $^{16}$ and Thr $^{17}$ residues; pRYR Ser ${ }^{2809}=$ phosphorylated ryanodyne at the Ser ${ }^{2809}$ residue; NFAT = nuclear factor of activated T-cells; PI3K = phosphatidylinositol 3-kinases; Akt $=$ protein kinase $\mathrm{B}$.

\section{Impact of exercise training on cardiac remodeling}

Pathological cardiac remodeling is an adaptive response of the heart to a variety of extrinsic and intrinsic pathophysiological stimuli such as sustained neurohumoral activation, mechanical stress and genetic variations. Maladaptative remodeling is associated with cardiac dysfunction and HF, where sustained hypertrophy is an independent risk factor for HF development and sudden death (48). However, not all forms of cardiac hypertrophy are pathological since exercise training promotes a physiological cardiac hypertrophy associated with improved cardiac function in athletes.
Prolonged neurohumoral activation is the most prominent factor associated with pathological cardiac remodeling in HF. In fact, we and others have demonstrated that genetic and nongenetic animal models of neurohumoral overactivation result in remarkable maladaptive cardiac remodeling associated with ventricular dysfunction $(3,4)$. This concept is supported by findings from HF animal models and clinical trials showing that inhibition or regression of cardiac hypertrophy by drugs targeting neurohumoral systems (i.e., ACE inhibitors and $\beta$-blockers) lowers the risk for death and HF development $(4,9)$. Over the last few years, our group has reported that exercise training strikingly counteracts the deleterious effects of neurohumoral overactivation in HF. First, we showed that 8 weeks of aerobic 
exercise training significantly reduced sympathetic tone with a remarkable cardiac anti-remodeling effect in HF mice (18). Indeed, exercise training reduced cardiac angiotensin II levels by reducing local renin-angiotensin system activation in $\mathrm{HF} \mathrm{a}_{2 \mathrm{~A}}$ / $\alpha_{2 C}$ ARKO mice (21). This phenomenon was accompanied bya prominent reduction in both cardiac myocyte width and collagen deposition, which resulted in improved ventricular function in HF animals. In fact, our group and others have reported that aerobic exercise training markedly decreases resting circulating neurohormones in HF patients (15), which is one of the most valuable indicators of morbidity and mortality. Besides counteracting systemic and local neurohumoral hyper-activation in HF, exercise training directly benefits the failing heart by promoting a notable cardiac anti-remodeling effect.

Exercise training reverses maladaptive cardiac hypertrophy and improves ventricular function in HF, a fact that ultimately raises the possibility that exercise training actually promotes a shift from pathological to physiological cardiac remodeling in heart disease (17). Over the last decade, many groups have focused on deciphering the cellular basis of exercise traininginduced cardiac anti-remodeling in HF. Among thousands of proteins and cellular pathways present in the cardiomyocyte, two major signaling cascades have been emerged as key regulators of exercise training-associated cardiac hypertrophy in HF.

First, the calcineurin/nuclear factor of activated $T$ cell (NFAT) signaling cascade, which is the major player in pathological cardiac remodeling, is negatively regulated by exercise training (20). Calcineurin is a calcium/calmodulin-activated serine-threonine phosphatase that dephosphorylates and translocates NFAT transcriptional factors to the nucleus, which ultimately activates gene reprogramming and promotes maladaptive cardiac hypertrophy. We have first reported that aerobic exercise training deactivates the cardiac calcineurin/ NFAT signaling pathway in HF mice, resulting in a significant cardiac anti-remodeling effect accompanied by improved ventricular function (20). Of interest, exercise training promoted the same beneficial effects as induced by sustained treatment with cyclosporine (a selective inhibitor of the calcineurin/NFAT pathway) in HF (20). In agreement with our findings, Konhilas et al. (49) demonstrated that voluntary exercise decreased NFAT activation and reversed cardiac disease phenotypes in an animal model of hypertrophic cardiomyopathy. These findings clearly demonstrate that deactivation of the calcineurin/NFAT signaling pathway is a key process involved in the exercise training-induced cardiac anti-remodeling effect in HF.

Unlike the calcineurin/NFAT pathway, the phosphoinositide-3 kinase/protein kinase B (PI3K/Akt) signaling cascade contributes to physiological cardiac remodeling with gain of cardiac function (50). Activation of the PI3K/Akt signaling pathway leads to cardiac hypertrophy by activating and deactivating the mammalian target of rapamycin (mTOR) and glycogen synthase kinase 3(GSK-3), respectively. In fact, overexpression of an activated form ofAkt leads to myocardial hypertrophy with improved cardiac function (51), whereas disruption of the Akt-1 gene abrogates cardiac hypertrophy in response to exercise training (52). Kemi et al. (50) demonstrated that changes in the cardiacPI3K/Akt signaling pathway distinguished physiological from maladaptive cardiac hypertrophy (50). We have recently reported that the PI3K/Akt signaling pathway is not required to promote exercise training-induced cardiac anti-remodeling in HF (20). This result was somehow unexpected, but factors such as exercise training intensity and stage of cardiomyopathy may contribute to the lack of activation of the PI3K/Akt signaling pathway by exercise training in our HF animal model.

Taken together, these findings support the notion that deactivation and overactivation of maladaptive and physiological hypertrophy signaling cascades, respectively, are remarkable mechanisms underlying the cardiac anti-remodeling effect of exercise training in HF. Therefore, considering the variety of cross talking proteins and multiple signaling pathways in cardiac cells, additional research is required to better understand the effect of exercise training on the vast cellular basis involved in maladaptive and physiological cardiac remodeling in HF.

\section{Impact of exercise training on skeletal muscle myopathy}

Although cardiac dysfunction plays a crucial role in HF syndrome, indexes of left ventricular function relate poorly to exercise capacity and symptoms, suggesting that the origin of HF symptoms may lie elsewhere (53). In fact, skeletal myopathy plays a prominent role in HF symptoms since it worsens with HF progression and parallels exercise intolerance observed in HF individuals (54). In HF, skeletal myopathy affects large and small muscles involved in posture, locomotion and respiration. It has been characterized by reduced muscle endurance associated with a pro-oxidant and pro-inflammatory state, nutritional disorders, exercise intolerance, mitochondrial dysfunction, capillary rarefaction, and altered fiber phenotype with globally reduced type I slow twitch and increased type II fast twitch fibers (55). Furthermore, changes in excitation-contraction coupling and muscle atrophy are also associated with muscle dysfunction and reduced strength (55). Taken together, these changes contribute to the increased muscle fatigability and lactate accumulation in response to exercise in HF.

Over the last few years, our group has demonstrated that sympathetic hyperactivity contributes to skeletal myopathy. First, we showed that sympathetic activation contributes to chronic vasoconstriction in HF patients at rest and during exercise or mental challenge (15). In sympathetic hyperactivityinduced HF mice, we showed a skeletal muscle pro-oxidant state (marked by decreased redox balance and increased lipid hydroperoxidation), soleus and plantaris atrophy, capillary rarefaction, increased fast/glycolytic fibers, reduced oxidative capacity, and exercise intolerance (22).

Aerobic exercise training is a powerful tool counteracting skeletal muscle myopathy. It decreased resting sympathetic nerve activity paralleled by a significant increased forearm blood flow and exercise capacity in HF patients (15). In ani- 
mals, we observed reduced muscle noradrenaline levels and oxidative stress associated with improved exercise capacity and re-established muscle trophicity (22).

In addition to affecting sympathetic activity, exercise training also prevents skeletal muscle abnormalities by other mechanisms. The increased content of oxidative enzymes and mitochondria induced by aerobic exercise training rescues the oxidative capacity, which ultimately leads to an improved $\mathrm{VO}_{2}$ peak and lactate threshold in animal and human HF (56). The peroxisome proliferator-activated receptor $\mathrm{y}$ coactivator-1a (PGC-1 $\alpha$ ) is a key molecule in the regulation of mitochondrial biogenesis and its signaling pathway seems to be activated by aerobic exercise training (57). Indeed, a reduced inducible nitric oxide synthase (iNOS) expression also plays an important role, since iNOS-induced intracellular NO accumulation inhibits key enzymes of oxidative phosphorylation (22). A summary of the main mechanisms involved in the effects of exercise training on HF skeletal myopathy is shown in Figure 3.
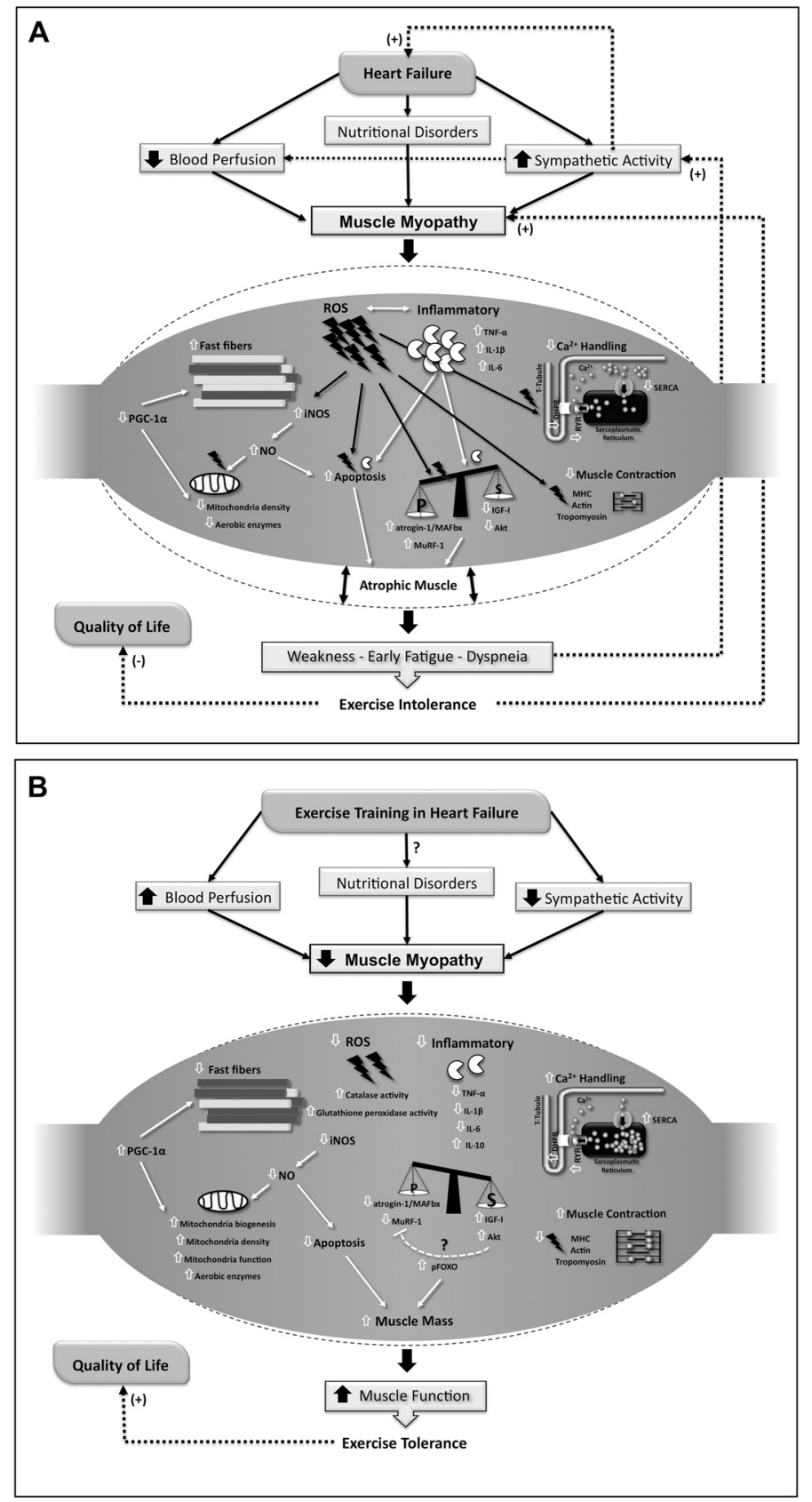

Figure 3. Effect of aerobic exercise training on heart failure-induced skeletal muscle myopathy. Sympathetic hyperactivity, reduced blood perfusion and nutritional disorders associated with heart failure contribute to skeletal muscle myopathy, which is characterized by muscle pro-oxidant (increased ROS) and pro-inflammatory (increased pro-inflammatory cytokines such as TNF- $\alpha$, IL$1 \beta$ and IL-6) state associated with contraction dysfunction and atrophy, weakness, exercise intolerance, and early fatigue (A). These responses are associated with increased iNOS, increased PGC-1a, mitochondrial dysfunction, impaired $\mathrm{Ca}^{2+}$ handling, apoptosis and reduced protein synthesis paralleled by increased proteolysis (A). Note that aerobic exercise training counteracts most of the mechanisms involved in skeletal myopathy (B). $\mathrm{ROS}=$ reactive oxygen species; $\mathrm{PGC}-1 \alpha=$ peroxisome proliferator-activated receptor $\gamma$ coactivator- $1 \alpha$; iNOS = inducible nitric oxide synthase; NO = nitric oxide; TNF- $\alpha$ $=$ tumor necrosis factor- $\alpha$; IL-1 $\beta=$ interleukin- $1 \beta$; IL- $6=$ interleukin-6; IL-10 = interleukin-10; RYR = ryanodyne receptor; DHPR = dihydropyridine receptor; SERCA = sarcoplasmic reticulum $\mathrm{Ca}^{2+}$ ATPase; T-Tubule $=$ transverse tubule; $\mathrm{MHC}=$ myosin heavy chain; $\mathrm{P}=$ proteolysis; $S$ = synthesis; IGF-I = insulin-like growth factor-1; $\mathrm{pFOXO}=$ phosphorylated forkhead family of transcription factors; Akt = protein kinase B; Atrogin-1/MAFbx = muscle atrophy F-box protein; MuRF-1 = muscle RINGfinger protein-1. 
Alterations in excitation-contraction coupling and protein synthesis/degradation balance have also been proposed to contribute to skeletal muscle fatigability and weakness in HF (Figure 3). In severe HF rats, decreased skeletal muscle sarcoplasmic $\mathrm{Ca}^{2+}$ levels were associated with a reduced rate of sarcoplasmic reticulum $\mathrm{Ca}^{2+}$ release (58) and reuptake (59). This response is partially explained by reduced expression of proteins involved in intracellular $\mathrm{Ca}^{2+}$ homeostasis in skeletal muscles consisting of different fiber types such as soleus and plantaris muscles (predominantly oxidative and glycolytic muscles, respectively) (23). Interestingly, we have demonstrated that aerobic exercise training improves the net balance of skeletal muscle $\mathrm{Ca}^{2+}$-handling proteins in mice (60). Moreover, exercise training restores the expression levels of proteins involved in sarcoplasmic $\mathrm{Ca}^{2+}$ release and reuptake in soleus and plantaris muscles from HF mice (23). This ultimately leads to improved skeletal muscle function (23). Regarding skeletal muscle atrophy, even aerobic exercise training is able to re-establish soleus and plantaris trophicity in our sympathetic hyperactivityinduced HF mouse model $(22,23)$. This is somewhat surprising since resistance and not aerobic exercise training swings the protein synthesis/degradation balance in favor of protein synthesis. However, one might consider that, in $\mathrm{HF}$, skeletal muscle bulk is reduced and even the aerobic exercise stimulus may be enough to abrogate atrophy. Nevertheless, aerobic exercise rather than high intensity resistance training is recommended for HF patients in view of its impact on the hemodynamic responses to exercise. The mechanism by which aerobic exercise training prevents/ attenuates skeletal muscle atrophy has not been clarified. Activation of the IGF-1/PI3K/Akt signaling pathway is a good candidate since it stimulates protein synthesis and aerobic exercise training is able to restore decreased muscle IGF-1 expression in stable HF patients to control subject levels (61). In fact, preliminary data from our laboratory point to an increased Akt phosphorylation in HF mice after 2 months of aerobic exercise training (Bacurau $A$, unpublished results). In addition, aerobic exercise training might reduce protein catabolism, which would favor a pro-protein synthesis state. Supporting this notion, ongoing studies from our laboratory have shown that aerobic exercise training decreases $m R N A$ levels of the main skeletal muscle atrophic genes (MuRF

\section{References}

1. Lindenfeld J, Albert NM, Boehmer JP, Collins SP, Ezekowitz JA, Givertz MM, et al. HFSA 2010 Comprehensive Heart Failure Practice Guideline. J Card Fail 2010; 16: e1-e194.

2. Brum PC, Hurt CM, Shcherbakova OG, Kobilka B, Angelotti T. Differential targeting and function of alpha2A and alpha2C adrenergic receptor subtypes in cultured sympathetic neurons. Neuropharmacology 2006; 51: 397-413.

3. Brum PC, Kosek J, Patterson A, Bernstein D, Kobilka B. Abnormal cardiac function associated with sympathetic and Atrogin-1/MAFbx) (Cunha F, unpublished results).

Collectively, our studies and others suggest that aerobic exercise training promotes remarkable skeletal muscle adaptations in HF that counteract skeletal myopathy. Therefore, aerobic exercise training is a powerful nonpharmacological therapy for HF.

Taken together, our studies and those of others suggest that sympathetic hyperactivity plays a remarkable role in HF syndrome, being associated with cardiac dysfunction and remodeling, as well as skeletal myopathy $(4,14,15,17,18,22,23)$. Counteracting sympathetic hyperactivity is a goal of HF therapy. In this review, we describe the effects of aerobic exercise training on sympathetic nerve activity, which is reduced in exercise-trained HF patients (Figure 1). The reduction of sympathetic hyperactivity by aerobic exercise training is extended to our HF mouse model and is associated with improved cardiac function and reverse remodeling related to a better net balance of protein involved in $\mathrm{Ca}^{2+}$ homeostasis and deactivation of the calcineurin/NFAT signaling pathway, respectively (Figure 2). Further studies by our group and others have shown that sympathetic hyperactivity contributes to skeletal myopathy in HF $(22,23)$. Aerobic exercise training improves skeletal muscle function and prevents atrophy, and the mechanisms underlying these responses seem to involve reduction of a pro-oxidant state, improved $\mathrm{Ca}^{2+}$ homeostasis, mitochondrial function, and a synthesis/degradation balance swing in favor of protein synthesis (Figure 3). Therefore, aerobic exercise training is an efficient non-pharmacological therapy for HF and mechanisms underlying its beneficial effects are the focus of ongoing studies by our group.

\section{Acknowledgments}

Research supported by FAPESP (\#2002/04558-8, \#2005/59740-7, \#2006/61523-7) to P.C. Brum and C.E. Negrão, and Edital Universal CNPq (\#473251/2009-4) to P.C. Brum. A.V.N. Bacurau is the recipient of a doctoral scholarship from FAPESP (\#2008/50777-3), J.C.B. Ferreira is the recipient of a post-doctoral fellowship from FAPESP (\#2009/03143-1), and P.C. Brum is the recipient of a productivity fellowship from CNPq (\#BPQ 301519/2008-0). nervous system hyperactivity in mice. Am J Physiol Heart Circ Physiol 2002; 283: H1838-H1845.

4. Ferreira JC, Bacurau AV, Evangelista FS, Coelho MA, Oliveira EM, Casarini DE, et al. The role of local and systemic renin angiotensin system activation in a genetic model of sympathetic hyperactivity-induced heart failure in mice. $\mathrm{Am} \mathrm{J}$ Physiol Regul Integr Comp Physiol 2008; 294: R26-R32.

5. Barretto AC, Santos AC, Munhoz R, Rondon MU, Franco FG, Trombetta IC, et al. Increased muscle sympathetic 
nerve activity predicts mortality in heart failure patients. Int J Cardiol 2009; 135: 302-307.

6. De Matos LD, Gardenghi G, Rondon MU, Soufen HN, Tirone AP, Barretto AC, et al. Impact of 6 months of therapy with carvedilol on muscle sympathetic nerve activity in heart failure patients. J Card Fail 2004; 10: 496-502.

7. Anonymous. Effect of metoprolol $\mathrm{CR} / \mathrm{XL}$ in chronic heart failure: Metoprolol CR/XL Randomised Intervention Trial in Congestive Heart Failure (MERIT-HF). Lancet 1999; 353: 2001-2007.

8. Ferreira JC, Boer BN, Grimberg M, Brum PC, Mochly-Rosen $D$. Protein quality control disruption by $\mathrm{PKC} \beta \mathrm{II}$ in heart failure. ISHR North American Section Meeting; 2009.

9. Bartholomeu JB, Vanzelli AS, Rolim NP, Ferreira JC, Bechara LR, Tanaka LY, et al. Intracellular mechanisms of specific beta-adrenoceptor antagonists involved in improved cardiac function and survival in a genetic model of heart failure. J Mol Cell Cardiol 2008; 45: 240-249.

10. Crimi E, Ignarro LJ, Cacciatore F, Napoli C. Mechanisms by which exercise training benefits patients with heart failure. Nat Rev Cardiol 2009; 6: 292-300.

11. Bocchi EA, Braga FG, Ferreira SM, Rohde LE, Oliveira WA, Almeida DR, et al. [III Brazilian Guidelines on Chronic Heart Failure]. Arq Bras Cardiol 2009; 93: 3-70.

12. Negrao CE, Middlekauff HR. Exercise training in heart failure: reduction in angiotensin II, sympathetic nerve activity, and baroreflex control. J Appl Physiol 2008; 104: 577-578

13. Rondon E, Brasileiro-Santos MS, Moreira ED, Rondon MU, Mattos KC, Coelho MA, et al. Exercise training improves aortic depressor nerve sensitivity in rats with ischemia-induced heart failure. Am J Physiol Heart Circ Physiol 2006; 291: H2801-H2806.

14. Fraga R, Franco FG, Roveda F, de Matos LN, Braga AM, Rondon $\mathrm{MU}$, et al. Exercise training reduces sympathetic nerve activity in heart failure patients treated with carvedilol. Eur J Heart Fail 2007; 9: 630-636.

15. Roveda F, Middlekauff HR, Rondon MU, Reis SF, Souza M, Nastari $L$, et al. The effects of exercise training on sympathetic neural activation in advanced heart failure: a randomized controlled trial. J Am Coll Cardiol 2003; 42: 854-860.

16. Jorge L, Rodrigues B, Rosa KT, Malfitano C, Loureiro TC, Medeiros A, et al. Cardiac and peripheral adjustments induced by early exercise training intervention were associated with autonomic improvement in infarcted rats: role in functional capacity and mortality. Eur Heart J 2011; 32: 904912.

17. Medeiros A, Rolim NP, Oliveira RS, Rosa KT, Mattos KC, Casarini $\mathrm{DE}$, et al. Exercise training delays cardiac dysfunction and prevents calcium handling abnormalities in sympathetic hyperactivity-induced heart failure mice. J Appl Physiol 2008; 104: 103-109.

18. Rolim NP, Medeiros A, Rosa KT, Mattos KC, Irigoyen MC, Krieger EM, et al. Exercise training improves the net balance of cardiac $\mathrm{Ca}^{2+}$ handling protein expression in heart failure. Physiol Genomics 2007; 29: 246-252.

19. Medeiros A, Vanzelli AS, Rosa KT, Irigoyen MC, Brum PC. Effect of exercise training and carvedilol treatment on cardiac function and structure in mice with sympathetic hyperactivity-induced heart failure. Braz $J$ Med Biol Res 2008; 41: 812-817.

20. Oliveira RS, Ferreira JC, Gomes ER, Paixao NA, Rolim NP, Medeiros A, et al. Cardiac anti-remodelling effect of aerobic training is associated with a reduction in the calcineurin/ NFAT signalling pathway in heart failure mice. J Physiol 2009; 587: 3899-3910.

21. Pereira MG, Ferreira JC, Bueno CR Jr, Mattos KC, Rosa $\mathrm{KT}$, Irigoyen MC, et al. Exercise training reduces cardiac angiotensin II levels and prevents cardiac dysfunction in a genetic model of sympathetic hyperactivity-induced heart failure in mice. Eur J Appl Physiol 2009; 105: 843-850.

22. Bacurau AV, Jardim MA, Ferreira JC, Bechara LR, Bueno CR Jr, Alba-Loureiro TC, et al. Sympathetic hyperactivity differentially affects skeletal muscle mass in developing heart failure: role of exercise training. J Appl Physiol 2009; 106: 1631-1640.

23. Bueno CR Jr, Ferreira JC, Pereira MG, Bacurau AV, Brum $P C$. Aerobic exercise training improves skeletal muscle function and $\mathrm{Ca}^{2+}$ handling-related protein expression in sympathetic hyperactivity-induced heart failure. J Appl Physiol 2010; 109: 702-709.

24. Lopes RD, Batista ML Jr, Rosa JC, Lira FS, Martins E $\mathrm{Jr}$, Shimura AY, et al. Changes in the production of IL-10 and TNF-alpha in skeletal muscle of rats with heart failure secondary to acute myocardial infarction. Arq Bras Cardiol 2010; 94: 293-320.

25. Coats AJ, Adamopoulos S, Radaelli A, McCance A, Meyer TE, Bernardi L, et al. Controlled trial of physical training in chronic heart failure. Exercise performance, hemodynamics, ventilation, and autonomic function. Circulation 1992; 85: 2119-2131.

26. Radaelli A, Coats AJ, Leuzzi S, Piepoli M, Meyer TE, Calciati $A$, et al. Physical training enhances sympathetic and parasympathetic control of heart rate and peripheral vessels in chronic heart failure. Clin Sci 1996; 91 (Suppl): 92-94.

27. Lara A, Damasceno DD, Pires R, Gros R, Gomes ER, Gavioli $M$, et al. Dysautonomia due to reduced cholinergic neurotransmission causes cardiac remodeling and heart failure. Mol Cell Biol 2010; 30: 1746-1756.

28. Serra SM, Costa RV, Teixeira De Castro RR, Xavier SS, Nobrega AC. Cholinergic stimulation improves autonomic and hemodynamic profile during dynamic exercise in patients with heart failure. J Card Fail 2009; 15: 124-129.

29. Brum PC, Da Silva GJ, Moreira ED, Ida F, Negrao CE, Krieger EM. Exercise training increases baroreceptor gain sensitivity in normal and hypertensive rats. Hypertension 2000; 36: 1018-1022.

30. Liu JL, Irvine S, Reid IA, Patel KP, Zucker IH. Chronic exercise reduces sympathetic nerve activity in rabbits with pacing-induced heart failure: A role for angiotensin II. Circulation 2000; 102: 1854-1862.

31. Negrao CE, Irigoyen MC, Moreira ED, Brum PC, Freire PM, Krieger EM. Effect of exercise training on RSNA, baroreflex control, and blood pressure responsiveness. Am J Physiol 1993; 265: R365-R370.

32. Piepoli M, Clark AL, Volterrani M, Adamopoulos S, Sleight $P$, Coats AJ. Contribution of muscle afferents to the hemodynamic, autonomic, and ventilatory responses to exercise in patients with chronic heart failure: effects of physical training. Circulation 1996; 93: 940-952.

33. Pliquett RU, Cornish KG, Patel KP, Schultz HD, Peuler JD, Zucker IH. Amelioration of depressed cardiopulmonary reflex control of sympathetic nerve activity by short-term exercise training in male rabbits with heart failure. $J \mathrm{Appl}$ Physiol 2003; 95: 1883-1888. 
34. Schultz HD, Sun SY. Chemoreflex function in heart failure. Heart Fail Rev 2000; 5: 45-56.

35. Silva GJ, Brum PC, Negrao CE, Krieger EM. Acute and chronic effects of exercise on baroreflexes in spontaneously hypertensive rats. Hypertension 1997; 30: 714-719.

36. Liu JL, Kulakofsky J, Zucker IH. Exercise training enhances baroreflex control of heart rate by a vagal mechanism in rabbits with heart failure. J Appl Physiol 2002; 92: 2403-2408.

37. Michelini LC, Stern JE. Exercise-induced neuronal plasticity in central autonomic networks: role in cardiovascular control. Exp Physiol 2009; 94: 947-960.

38. Kar S, Gao L, Zucker IH. Exercise training normalizes ACE and ACE2 in the brain of rabbits with pacing-induced heart failure. J Appl Physiol 2010; 108: 923-932.

39. van Tol BA, Huijsmans RJ, Kroon DW, Schothorst M, Kwakkel G. Effects of exercise training on cardiac performance, exercise capacity and quality of life in patients with heart failure: a meta-analysis. Eur J Heart Fail 2006; 8: 841-850.

40. Haykowsky MJ, Liang Y, Pechter D, Jones LW, McAlister FA, Clark AM. A meta-analysis of the effect of exercise training on left ventricular remodeling in heart failure patients: the benefit depends on the type of training performed. J Am Coll Cardiol 2007; 49: 2329-2336.

41. Santos JM, Kowatsch I, Tsutsui JM, Negrao CE, Canavesi $\mathrm{N}$, Carvalho FC, et al. Effects of exercise training on myocardial blood flow reserve in patients with heart failure and left ventricular systolic dysfunction. Am J Cardiol 2010; 105: 243-248.

42. Rigo F, Gherardi S, Galderisi M, Sicari R, Picano E. The independent prognostic value of contractile and coronary flow reserve determined by dipyridamole stress echocardiography in patients with idiopathic dilated cardiomyopathy. Am J Cardiol 2007; 99: 1154-1158.

43. Wisloff U, Stoylen A, Loennechen JP, Bruvold M, Rognmo O, Haram PM, et al. Superior cardiovascular effect of aerobic interval training versus moderate continuous training in heart failure patients: a randomized study. Circulation 2007; 115: 3086-3094.

44. Haghighi K, Schmidt AG, Hoit BD, Brittsan AG, Yatani A, Lester JW, et al. Superinhibition of sarcoplasmic reticulum function by phospholamban induces cardiac contractile failure. J Biol Chem 2001; 276: 24145-24152.

45. Marks AR. A guide for the perplexed: towards an understanding of the molecular basis of heart failure. Circulation 2003; 107: 1456-1459.

46. Zhang LQ, Zhang XQ, Musch TI, Moore RL, Cheung JY. Sprint training restores normal contractility in postinfarction rat myocytes. J Appl Physiol 2000; 89: 1099-1105.

47. Kemi OJ, Wisloff $U$. High-intensity aerobic exercise training improves the heart in health and disease. J Cardiopulm Rehabil Prev 2010; 30: 2-11.

48. Lorell BH, Carabello BA. Left ventricular hypertrophy: patho- genesis, detection, and prognosis. Circulation 2000; 102: 470-479.

49. Konhilas JP, Watson PA, Maass A, Boucek DM, Horn T, Stauffer BL, et al. Exercise can prevent and reverse the severity of hypertrophic cardiomyopathy. Circ Res 2006; 98 : 540-548.

50. Kemi OJ, Ceci M, Wisloff U, Grimaldi S, Gallo P, Smith GL, et al. Activation or inactivation of cardiac Akt/mTOR signaling diverges physiological from pathological hypertrophy. J Cell Physiol 2008; 214: 316-321.

51. Latronico MV, Costinean S, Lavitrano ML, Peschle C, Condorelli G. Regulation of cell size and contractile function by AKT in cardiomyocytes. Ann N Y Acad Sci 2004; 1015: 250260.

52. McMullen JR, Shioi T, Zhang L, Tarnavski O, Sherwood MC, Kang PM, et al. Phosphoinositide 3-kinase(p110alpha) plays a critical role for the induction of physiological, but not pathological, cardiac hypertrophy. Proc Natl Acad Sci U S A 2003; 100: 12355-12360.

53. Harrington D, Coats AJ. Skeletal muscle abnormalities and evidence for their role in symptom generation in chronic heart failure. Eur Heart J 1997; 18: 1865-1872.

54. Meyer FJ, Borst MM, Zugck C, Kirschke A, Schellberg D, Kubler W, et al. Respiratory muscle dysfunction in congestive heart failure: clinical correlation and prognostic significance. Circulation 2001; 103: 2153-2158.

55. Vescovo G, Volterrani M, Zennaro R, Sandri M, Ceconi C, Lorusso R, et al. Apoptosis in the skeletal muscle of patients with heart failure: investigation of clinical and biochemical changes. Heart 2000; 84: 431-437.

56. Gustafsson T, Kraus WE. Exercise-induced angiogenesisrelated growth and transcription factors in skeletal muscle, and their modification in muscle pathology. Front Biosci 2001; 6: D75-D89.

57. Liang $\mathrm{H}$, Ward WF. PGC-1alpha: a key regulator of energy metabolism. Adv Physiol Educ 2006; 30: 145-151.

58. Perreault CL, Gonzalez-Serratos H, Litwin SE, Sun X, Franzini-Armstrong $\mathrm{C}$, Morgan JP. Alterations in contractility and intracellular $\mathrm{Ca}^{2+}$ transients in isolated bundles of skeletal muscle fibers from rats with chronic heart failure. Circ Res 1993; 73: 405-412.

59. Lunde PK, Sjaastad I, Schiotz Thorud HM, Sejersted OM. Skeletal muscle disorders in heart failure. Acta Physiol Scand 2001; 171: 277-294.

60. Ferreira JC, Bacurau AV, Bueno CR Jr, Cunha TC, Tanaka LY, Jardim MA, et al. Aerobic exercise training improves $\mathrm{Ca}^{2+}$ handling and redox status of skeletal muscle in mice. Exp Biol Med 2010; 235: 497-505.

61. Schulze PC, Gielen S, Schuler G, Hambrecht R. Chronic heart failure and skeletal muscle catabolism: effects of exercise training. Int J Cardiol 2002; 85: 141-149. 